
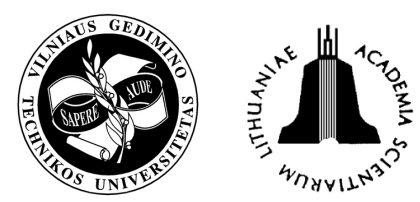

ISSN 1648-4142 print / ISSN 1648-3480 online TRANSPORT

www.transport.vgtu.lt

\title{
ELECTRODYNAMIC BRAKING IN HIGH-SPEED RAIL TRANSPORT
}

\author{
Lionginas Liudvinavičius ${ }^{1}$, Leonas Povilas Lingaitis ${ }^{2}$ \\ Dept of Railway Transport, Vilnius Gediminas Technical University, J. Basanavičiaus g. 28 \\ LT-03224 Vilnius, Lithuania \\ E-mails: ${ }^{1}$ geltr@ti.vgtu.lt; ${ }^{2}$ leonasl@ti.vgtu.lt
}

Received 26 January 2007; accepted 2 May 2007

\begin{abstract}
The paper considers electrodynamic braking of trains, which is of particular importance for high-speed railway transport from theoretical and technical perspectives. Braking methods used for high-speed trains should ensure compatibility and redundancy of braking systems. They include a mechanical method (based on adding frictional disks to wheelsets), as well as magnetic braking, which is being currently implemented and based on eddy currents, etc. High-speed trains have AC/DC engines, for which the principles of electric braking can be applied. Electrodynamic braking is of particular importance for high-speed transport using linear motors and developing the speed of $400-500 \mathrm{~km} / \mathrm{h}$. These traction rolling stocks will not have commonly used trucks. The tests in this area are being conducted in Japan and Germany now. The paper suggests some theoretical and practical solutions to these problems. Schematic diagrams of the locomotive braking and ways of controlling the braking force by varying electric circuit parameters are presented. The authors suggested contact-free regulation of braking rheostat resistor for controlling braking force in rheostatic braking. A schematic diagram of harmonizing electrified railways and power system's upgrading aimed at ensuring power regeneration is also presented.
\end{abstract}

Keywords: voltage, contact system, current, braking force, moment, inverter, power system, braking resistors, thyristor, electrodynamic braking.

\section{Introduction}

Preparing to start the construction of a European railway which will link the EU states with Scandinavian countries (via Poland, Lithuania, Latvia and Estonia), and purchasing high-speed trains for this railway line, such as SIEMENS diesel locomotives, ŠKODA two-storeyed electric trains and trams for Vilnius [1], as well as upgrading old models, specialists and politicians should provide more knowledge about electrodynamic braking and its advantages and disadvantages. It is also necessary to define possible obstacles in track circuits and to provide for some compensating technical measures. Theoretical and practical knowledge in the discussed area would be useful in adopting strategic development projects which should not become obsolete for at least 50 years. The advantages of electrodynamic braking should be taken into account in planning the integration of Lithuanian and EU railway systems:

1. So far, theoretical principles of electrodynamic braking system have not been thoroughly investigated (particularly, for AC traction motors, which are now being introduced by famous rolling stock manufacturers, e. g. SIEMENS, BOMBARDIER TRANSPORTATION, ALSTOM, MITSUBISHI ELECTRIC, etc.).
2. Most of the existing power systems are not well prepared to accept regenerative brake systems and return energy to the power system.

3. Economic indicators of electrodynamic braking have not been fully assessed, since, when common (pneumatic) braking systems, requiring the compressed air (obtained at the expense of power needed to rotate the compressor), are used, some elements of the system of levers are deteriorating. In addition, pneumatic cylinders for storing the compressed air and other equipment are required, though power (up to $10 \mathrm{MW}$ per locomotive) developed in the traction mode can be used in the braking mode without any restrictions.

4. An essential difference between electrodynamic and traditional mechanical (pneumatic) braking, used for about 100 years, is the control of the braking force by adjusting the electrical parameters of traction motors.

5. The impact of electrodynamic braking on automation, telemechanics as well as communication and alarm systems (including automatic block-system) has not been accurately determined yet. 
The influence of braking current on rail circuits has not been widely discussed in the present paper.

\section{Methods of electrodynamic braking}

When the speed of rolling stock is increasing, braking with blocks becomes ineffective. Besides, it is not fully automated. In high-speed trains, the redundancy of all available braking systems is required, implying that electric braking is automatically replaced by a pneumatic braking system, and vice versa. Therefore, the interest in electrodynamic braking methods is continually growing. These methods are aimed at changing the operation of traction motors of the locomotive into the generator mode operation. Electric motors operating in the generator mode convert the kinetic energy of a locomotive into electric power, determining the type of electric braking, which may be either rheostatic or regenerative, depending on further use. Electrodynamic braking does not eliminate braking with blocks.

The use of electrodynamic braking is, for example, unavoidable in underground railways because commonly used braking causes dust formation, thereby polluting the air in the underground tunnel. Therefore, there are special requirements there to ventilation systems, trains, etc.

Electric braking may be divided into rheostatic, which is used in the low speed range (allowing theoretically a complete stop of the train) and regenerative, used in the high speed range and in electric trains, in particular.

In the case of electrical traction, regenerativerheostatic braking is used. This method allows the electric braking to be used from braking initiation up to the full stop of the train if it is moving at high speed.

The main advantages of electric braking are precise regulation of braking force, while controlling the circuit parameters, as well as high speed and stability of system operation. Braking can be controlled either by engine-driver or automatically, when the latter is only an observer. Now, when Lithuania integrated into transeuropean transport network, the next step will be the integration into ETEVS (European Rail Traffic Management System), embracing such systems as GSM-R (The Global System for Mobile communications Railways), GPS (Global Position System), controlled by the US Defense Department, GALILEO (European Satellite Navigation System), GLONAS (Globalnaja Navigacionaja Sputnikovaja Sistema), controlled by Russia [2], GNSS (Global Navigation Satellite System), etc. These major systems and subsystems are aimed at controlling all EU transport systems and, primarily, high-speed transeuropean trains, the braking of which makes an integral part of control.

\section{The requirements raised to electrodynamic braking systems}

Electrical braking systems should satisfy the following requirements: effective braking in the chosen speed range, flexible control and automatic regulation system, stable braking mode, easily operated electric drive and high reliability.

Electrodynamic braking has both advantages and disadvantages. Its specific feature is braking with one locomotive. Taking into account that braking force is larger than traction force (besides, all mechanical losses subtracted in traction are summed up in braking), longitudinal stability of rolling stock can sharply decrease, making the control of the brakes more complicated for the locomotive-driver. Therefore, this process is controlled by microprocessor under the supervision of the locomotive-driver.

When the braking force is concentrated on the locomotive wheelsets, power concentration, as well as power losses due to drag friction, sharply increase [3].

\section{Regenerative braking}

Regenerative braking is more energy-effective because power given to contact system is either used by another electric train or returned to power system. More than $25 \%$ of power used for traction can be returned to contact system.

Series excitation DC motor, most commonly used for traction, cannot operate during regenerative braking because, when the external load is decreased, the speed of the armature revolution increases stepwise (theoretically up to $\infty$ ). Thus, the conditions for the motor at idle to exceed point $n_{0}$ of torque-speed characteristic $n=f(M)$, which is required in regenerative braking, cannot be satisfied (see Fig 1).

The excitation winding of such a motor should be shifted to an independent power supply system. In this case, the excitation winding is powered from a separate electric motor or semiconductor power source.

Under the condition [4] when the moment of resistance $M_{s}=0$, the motor reaches the ideal no-load speed $n_{0}$.

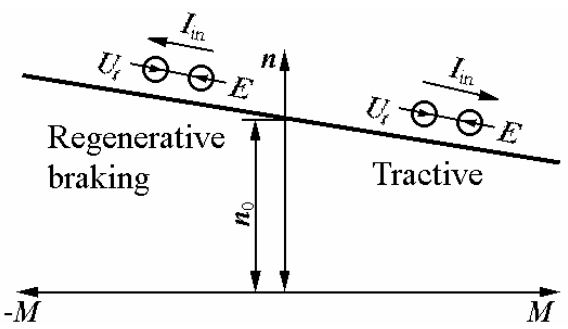

Fig 1. Torque-speed characteristic of shunt excitation motor's braking and traction modes: $n_{0}$ is motor's ideal no-load speed;

$U_{t}$ is contact system voltage; $I_{\text {in }}$ is armature current of traction motor

Disregarding the losses due to friction and electric motor's idle running, the electromotive force of the motor is equal to the voltage $U_{t}$ of the source of power, i.e. the contact system. When the load moment changes (e.g. when the locomotive is moving down the slope), the 
speed $n$ of the motor armature exceeds $n_{0}$, e.m.f. of the motor $E$ exceeds network voltage, the armature current is reversed and electromagnetic braking moment is developed (see Fig 1). The motor goes to the generator mode, while electromagnetic moment, which is a counter torque with respect to the armature, becomes a braking moment, and the power produced by generator is given to the contact system. In this way, the main condition of regenerative braking, according to which the voltage of the electric train motor (operating in the generator mode) must be higher than the contact system voltage, is satisfied.

The power of modern electric trains, like TGV in France, ICE in Germany, and the motor car unit of electric locomotives reaches $10 \mathrm{MW}$, therefore, brake horse power is very high. It can be found from the power balance equation as follows:

$$
P_{m}=P_{e}+\Delta P,
$$

where $P_{m}$ is the mechanical power of the motor shaft, $\mathrm{W} ; P_{e}$ is the electric power given to electricity supply network, $\mathrm{W} ; \Delta P$ is denotes total power losses of the electric circuit of the motor, $\mathrm{W}$.

Therefore, the power returned during the regenerative braking should be used by another traction locomotive. Otherwise, if no other train is found on a particular section of the contact system, there is no regenerative current flow there and the electric braking does not work (this is an inadmissible mode in rail transport). In this case, some specific requirements are raised to power system. In particular, the regenerative brake power should be returned to substation transformer and power system by specially installed inverters or used by ballast resistors. In the latter case, the regenerated power adds to electrical energy losses.

In most of the electrified railways of the developed countries of Europe, America and Asia, power can be returned to the electric power supply system for further use during regenerative braking. Some of the older electrified railways are upgraded by installing automatically operating inverters which should return the excessive power in the contact system to the electric power system (if no other train can use it for traction), so that it should not be lost in the ballast resistors at the substations.

For returning energy to electric power system in braking (in any case, irrespective of the availability or absence of an electric locomotive) the authors suggest to upgrade traction substation of a common electric power system by installing current inverters helping to return power to the electric power system instead of ballast resistors, where energy is lost (when there is no electric locomotive to use it) (see Fig 2) [5].

The key elements of the suggested scheme are: transformer substations, controlled rectifiers, inverters, high-speed DC breaker units.

According to the above scheme, all energy obtained in regenerative braking will be used for traction or returned to electric power system.

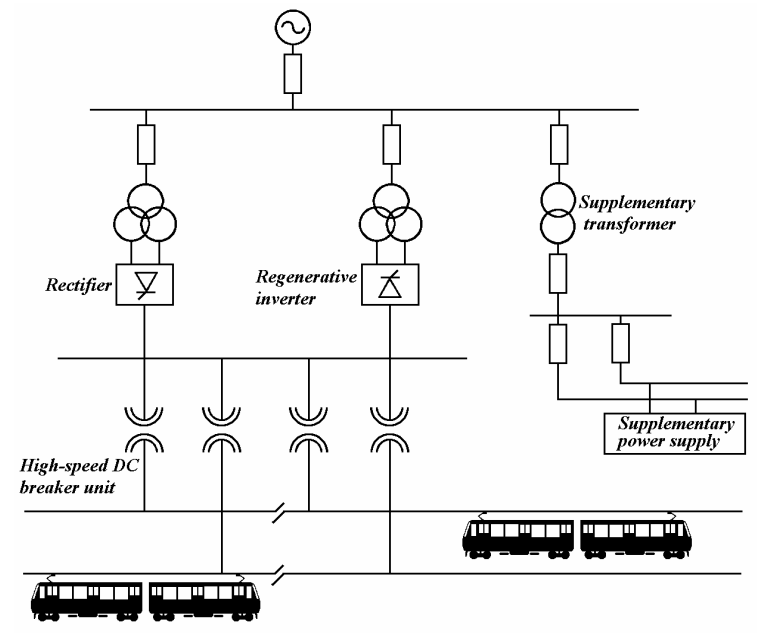

Fig 2. A scheme of linking electric power system and electrified railway

The operation of shunt excitation generators during regenerative braking is stable and reliable, though their characteristic $U_{r}=f\left(I_{s t}\right)$ (see Fig 3, curve 1) is not acceptable to electric locomotives because of considerable variation of braking force $\Delta B_{s t}$ caused by the variation of contact system voltage. This is because, actually, the voltage of the power supply contact system varies to a large extent.

The external characteristic of the generator used should be "sharply dropping" (e. g. characteristic a-b-c in Fig 3, curve 2). To avoid the impact of contact system voltage variation on the braking force (motor armature current), an appropriate excitation method of traction motor should be used when contact system voltage changes.

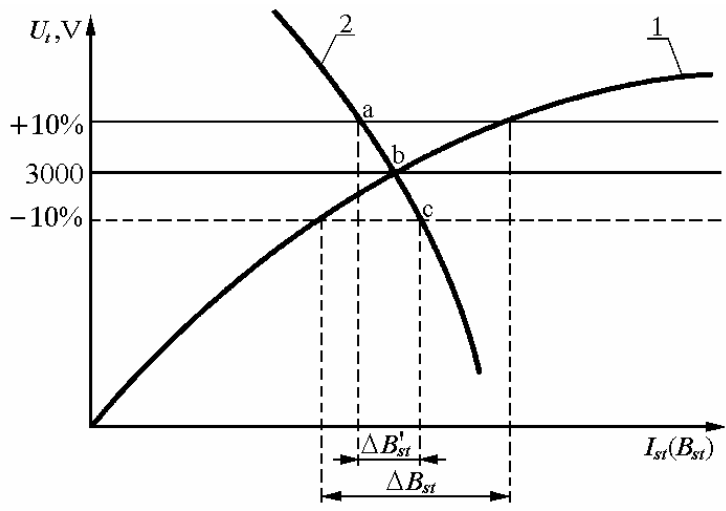

Fig 3. Regenerative braking control by using a special excitation generator (with the characteristic a-b-c)

A circuit for the appropriate excitation of the motor during regenerative braking may be obtained by using a special excitation generator with windings directed oppositely (see Fig 4).

When contact system voltage decreases and regenerative current $I_{\text {in }}$ increases, the excitation generator ZG will work in a demagnetizing mode due to op positely directed action of magnetomotive forces of the 


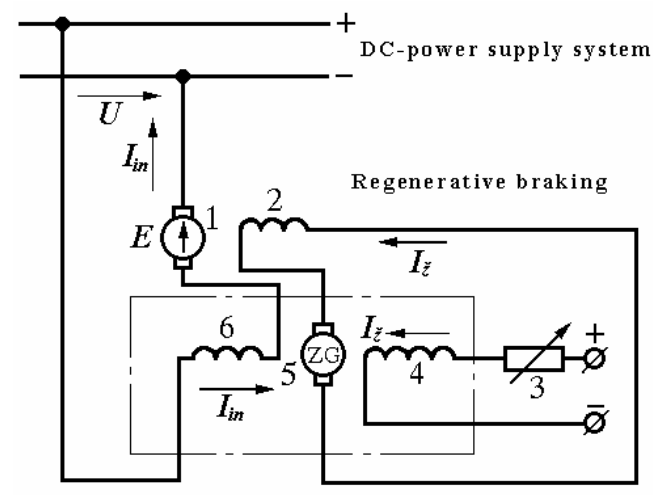

Fig 4. The connection of traction motor and special excitation generator during regenerative braking: 1 - traction motor;

2 - traction motor's excitation winding; 3 - controlled resistor; 4, 6- excitation windings with oppositely directed magnetomotive forces of DC mixed excitation generator (see current direction of windings 4 and 6 in Fig 4); 5 - excitation generator; $I_{\text {in }}$ - armature (regenerative) current of traction motor operating in generator mode; $I_{z}$ - excitation current of traction motor operating in generator mode

windings 6 and 2 (see current direction in Fig 4). The magnetic flux of traction motor will also decrease.

The same situation can be observed when the voltage of the contact system increases.

Characteristic 1 reflects the change in braking force $\Delta B_{s t}$ caused by the variation of contact system voltage, when a special type of excitation generator is not used. Characteristic 2 shows the change in the braking force $\Delta B_{s t}^{\prime}$, when a special excitation generator is used during regenerative braking (see Fig 3).

\section{Rheostatic braking}

In rheostatic braking [6], traction motors operate in DC series or separate generator excitation modes. Series excitation of generators is used in most of electric train traction motors.

Resistors used in starting are also used in rheostatic braking of electric locomotive drives.

Rheostatic braking of motors is feasible for both high and low armature speed, i.e. for low and high lo- comotive speed, because the voltage of traction motor operating in generator mode does not depend on the supply voltage and can be set according to the required braking force. Its value will depend on the locomotive speed, when it goes over to the braking mode.

To go over to rheostatic braking, the following conditions should be satisfied: series traction motor should be disconnected from the contact system in the electric drives of electric traction rolling stock (from generator in diesel locomotives); armature or excitation windings should be connected so that the excitation current would not change its direction (see Fig 5, b and c); traction motor should be connected to the dynamic braking resistor $R_{d s t}$.

When an electric motor goes over to the generator mode [4], the armature current $I_{\text {in }}$ changes sign, causing the breaking moment to occur (see the direction of moments $\mathrm{M}$ in Fig 5). If the terminals of armature or excitation windings are not changed, the DC serieswound motor will be demagnetized (i.e. residual magnetization will be cancelled out), when the armature current changes direction. As a result, the electric motor will not be able to operate in a series generator mode. When the circuits of armature and excitation windings are shifted according to diagrams b) and c) in Fig 5, the direction of excitation current $I_{z}$ remains unchanged, resulting in a steady excitation state due to residual magnetization.

Braking rheostat in electric traction rolling stock has several stages. Its impedance is adjusted by contactors, shunting separate elements. This type of control has quite a few disadvantages, the main of them being stepwise adjustment of rheostat resistor (stepwise adjustment of braking current $I_{i n}$ and braking force $B_{s t}$ ) and a great number of large-size commutators.

The locomotive braking force can be adjusted by controlling braking current $I_{s t}$ of traction motor. Usually, the resistors, which are used for traction, are employed in rheostatic braking of electric traction rolling stock. To achieve the highest speed uniformity, the starter rheostats are divided into separate stages (see Fig 6).

Braking of trains in railway traffic should be controlled, implying that braking force, which could take a

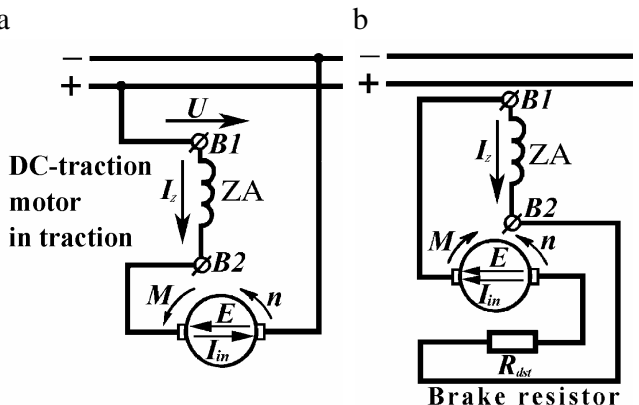

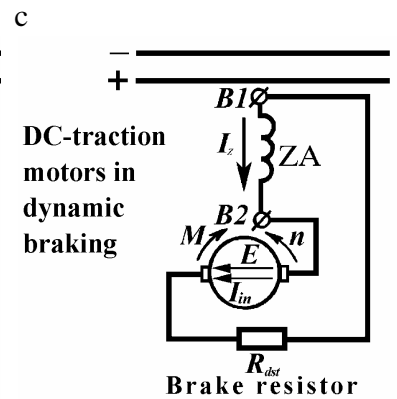

Fig 5. Diagrams showing series DC traction motor's changeover to dynamic (rheostat) braking mode: a - motor operation; $\mathrm{b}$ - dynamic braking mode with excitation winding shifted (ZA); $\mathrm{c}$ - dynamic braking mode with armature winding shifted 


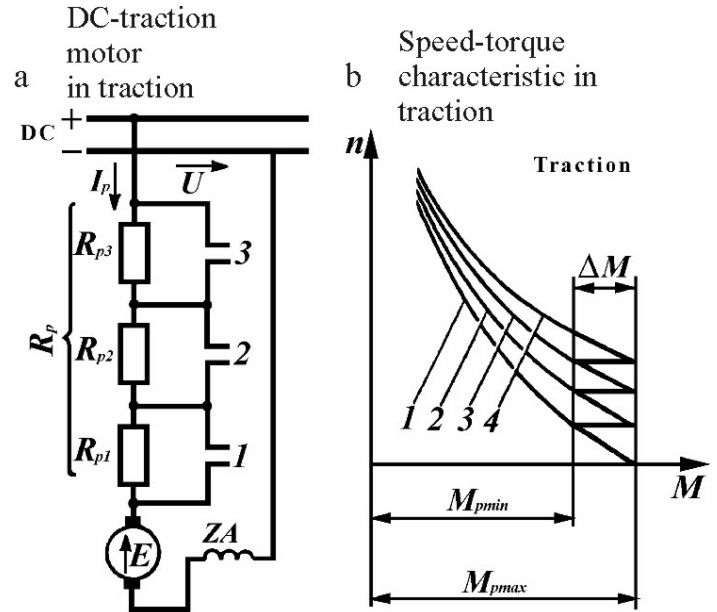

Fig 6. A circuit diagram of rheostat starting (traction mode) of DC series excitation motor (a) and its speed-torque characteristic $n=f(M)(\mathrm{b}): R_{p 1}, R_{p 2}, R_{p 3}$ - additional resistance; $1,2,3,4$ - contactors

into account all variables relating to braking and which could be adjusted, depending on the variation of the locomotive speed, rolling stock mass, road profile, etc. should be developed. Otherwise, the braking force could be insufficient for stopping the train in time, which might lead to failures and catastrophes (in industrial equipment braking of electric motors is usually uncontrolled, i.e. $R_{s t}=$ const ).

We suggest using a single rheostat $R_{p}$ (see Fig 7) with impulsive resistor regulation by semiconductor devices, such as thyristor and IGBI transistors operating in the key mode, to achieve automatic dynamic braking.

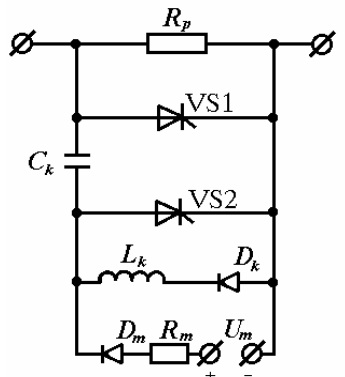

Fig 7. A circuit diagram of thyristor used for pulse regulation of braking rheostat resistor: VS2, $C_{k}, L_{k}, D_{m}, R_{m}, D_{k}-$ elements of forced thyristor VS1 commutation; $U_{m}$ - power supply source of forced commutation circuits

Thyristor is forcibly commutated so that the commutation period remains unchanged, while the relationship between the duration of disabling $t_{u z d}$ and enabling $t_{a t v}$ state of thyristor VS1 varies (see Fig 8). In other words, the width of the disabling pulse is being changed. This method of regulating braking resistor as an electric circuit parameter is also referred to as width- pulse modulation. Another method called pulsefrequency modulation can also be used. In this case, $t_{u z d}=$ const, while thyristor VS1 commutation period $T_{k}$, i.e. its commutation frequency, is changed. By changing the disabling period of thyristor, rheostat resistance can be smoothly changed from the peak value to $R_{p}=0$.

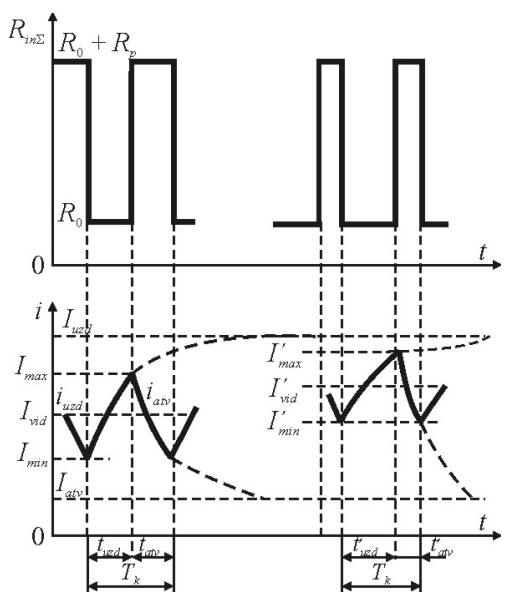

Fig 8. Diagrams showing the changes in rheostatic braking circuit parameter (resistor) during pulse regulation (a) and braking current (b)

Now, the impact of the relationship between the duration of the disabling and enabling thyristor VS1 states on the equivalent resistance in quasi-steady state should be determined. The resistance can be obtained from the following expression:

$$
R_{e k v}=\frac{E}{I_{v i d}},
$$

where $I_{v i d}$ is the average value of the enabling current of armature circuit, A.

$I_{\text {vid }}$ can be found as the average current value during the commutation period of thyristor:

$$
I_{v i d}=\frac{1}{T_{k}} \int_{0}^{T_{k}} i d t=\frac{1}{T_{k}\left(\int_{0}^{t_{u z d}} i_{u z d} d t+\int_{0}^{t_{a t v}} i_{a t v} d t\right)},
$$

where $i$ is instantaneous value of armature circuit; $i_{u z d}$, $i_{a t v}$ are stands for instantaneous values of armature circuit current for enabling and disabling states of thyristor VS1.

The variation of circuit disabling current can be expressed as:

$$
\begin{aligned}
& i_{u z d}=I_{u z d}-\left(I_{u z d}-I_{\min }\right) e^{-\frac{t}{T_{u z d}}}, \\
& i_{a t v}=I_{a t v}-\left(I_{a t v}-I_{\max }\right) e^{-\frac{t}{T_{a t v}}},
\end{aligned}
$$


where $I_{u z d}=\frac{E}{R_{0}+R_{p}}$ is the steady-state current value when the thyristor VS1 conducts current; $I_{a t v}=$ $\frac{E}{R_{0}+R_{p}}$ is the steady-state current value when the thyristor VS1 is disabled (the circuit is disconnected).

$I_{\min }$ and $I_{\max }$ can be obtained from the equations (4) and (5) by substituting $t=t_{u z d}$ in equation (4) and $t=t_{a t v}$ in equation (5):

$$
\begin{gathered}
I_{\max }=\frac{I_{u z d}\left(1-e^{-\frac{t_{u z z d}}{T_{u z d}}}\right)+I_{a t v}\left(1+e^{-\frac{t_{a t v}}{T_{a t v}}}\right) e^{-\frac{t_{u z d}}{T_{u z d}}}}{1-e^{-\left(\frac{t_{u z d}}{T_{u z d}}+\frac{t_{a t v}}{T_{a t v}}\right)},(6)} \\
I_{\min }=\frac{I_{u z d}\left(1-e^{-\frac{t_{u z d}}{T_{u z d}}}\right) e^{-\frac{t_{a t v}}{T_{a t v}}}+I_{a t v}\left(1-e^{-\frac{t_{a t v}}{T_{a t v}}}\right)}{1-e^{-\left(\frac{t_{u z d}}{T_{u z d}}+\frac{t_{a t v}}{T_{a t v}}\right)}} \text { (7) }
\end{gathered}
$$

Substituting the values of the currents $i_{u z d}$ and $i_{a t v}$ in equation (3), we get:

$$
\begin{aligned}
& I_{v i d}=\frac{1}{T_{k}}\left[I_{u z d} t_{u z d}+I_{a t v} t_{a t v}-\frac{\left(I_{u z d}-I_{a t v}\right)\left(T_{u z d}-T_{a t v}\right)}{1-e^{-\left(\frac{t_{u z d}}{T_{u z d}}+\frac{t_{a t v}}{T_{a t v}}\right)} \times}\right. \\
& \left.\left(1-e^{-\frac{t_{u z d}}{T_{u z d}}}\right)\left(1-e^{-\frac{t_{a t v}}{T_{a t v}}}\right)\right] .
\end{aligned}
$$

The expression obtained can be simplified because the circuit parameters are chosen in such a way that the commutation period $T_{k}$ is much shorter than the time constant $T_{a t v}\left(T_{k}<<T_{a t v}\right)$ of the armature circuit, when $R_{p}$ is connected. In addition, since $T_{u z d}>T_{a t v}$, then, $T_{k} \ll T_{u z d}$. Under such conditions, $t_{u z d} \ll<T_{u z d}$, $t_{a t v}<<T_{a t v}$, i.e. $\frac{t_{u z d}}{T_{u z d}}<<1$ and $\frac{t_{a t v}}{T_{a t v}} \ll<1$. Therefore, the deviation of instantaneous currents from the average value is insignificant, implying that the pulsing of current is low. On the other hand, taking into account the relationships obtained, we can change the exponential function power series in equation (8), leaving only the first two members of the series:

$$
e^{-\frac{t_{j}}{T_{j}}} \approx 1-\frac{t_{j}}{T_{j}} .
$$

Substituting $I_{u z d}, I_{a t v}, T_{u z d}$ and $T_{a t v}$ in equation (8) and taking into account that $t_{a t v}=T_{k}-t_{u z d}$, we get:

$$
I_{v i d}=\frac{T_{k} E}{T_{k} R_{0}+\left(T_{k}-t_{u z d}\right) R_{p}} .
$$

Then, (see 2):

$$
R_{e k v}=R_{0}+(1-\gamma) R_{p} \text {. }
$$

The equivalent additional resistor, characterizing the control parameter, is as follows:

$$
R_{p e k v}=R_{e k v}-R_{0}=(1-\gamma) R_{p} .
$$

Thus, by changing the disabling time of thyristor, additional equivalent (braking rheostat) resistor can be changed from $R_{p}\left(\gamma=0, t_{u z d}=0, t_{a t v}=T_{k}\right)$ to zero $\left(\gamma=1\right.$ or $\left.t_{u z d}=T_{k}\right)$.

The above statement is valid only for the finite $R_{p}$ value. It does not hold, when $R_{p} \rightarrow \infty$, i.e., when the connection of an additional resistor is equivalent to circuit interruption.

The analysis performed allows us to conclude that by changing pulse ratio $\gamma$, which in turn changes $R_{p e k v}$, the braking current (braking force) can be regulated with the required accuracy.

In using the above method, the main parameter of braking circuit - rheostat resistor will change according to the described regulation principle. The same applies to braking current $I_{s t}$ and braking force. High accuracy of braking force regulation can be achieved due to high speed of the system, using semiconductor elements (e. g. thyristors and IGBT transistors). Thyristor's commutation frequency is $f_{k}>20000 \mathrm{~Hz}$.

The use of traction generator in rheostatic diesel locomotive braking to feed the excitation windings of traction motors connected in series allows a circuit for separate excitation of rheostat motor braking to be made, when series excitation motors are disconnected from the power source (generator) and the windings of their armature are connected to individual braking rheostats. This can be achieved by setting braking regulator or controller to the mode of "Electric braking" when the switch SP connects armature windings 1-6 of traction motors to individual rheostats $R_{s t}$. Their resistors are usually not regulated during braking (a method of resistor regulation suggested by the authors of the present paper can also be applied to control rheostatic braking of diesel locomotives), while excitation motor windings 1-6 are connected in series and linked up to the output voltage of synchronous traction generatorrectifier (see Fig 9).

The developed rheostatic braking circuit design helps to continuously control speed and braking force in a wide range. This method is widely used in diesel locomotive $\mathrm{AC} / \mathrm{DC}$ electric motors. 


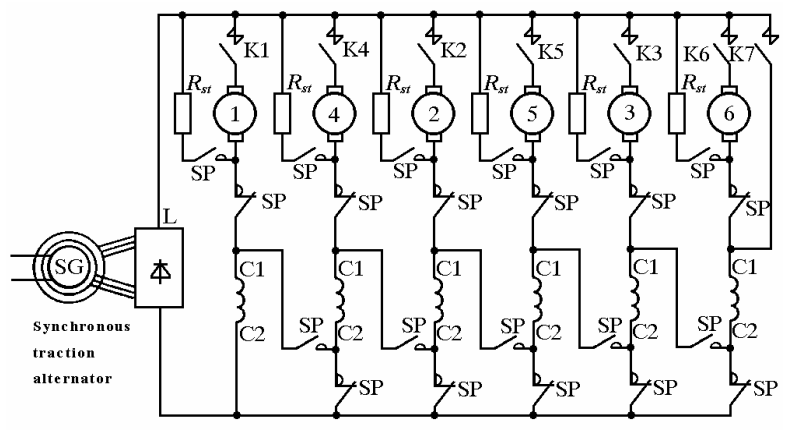

Fig 9. A circuit diagram of electrodynamic diesel locomotive braking: $\mathrm{SG}$ - synchronous traction alternator; $\mathrm{L}$ - rectifier; $R_{s t}$ - individual dynamic braking resistors; K1-K7 - starting contactors; $1-6$ - DC series excitation traction motors; $\mathrm{SP}$ - braking mode switch; $\mathrm{C} 1-\mathrm{C} 2$ - excitation windings of a particular traction motor

Braking force is regulated by changing the electric motor's parameters in the following way:

1. Altering the excitation current of traction generator, when shaft revolutions of diesel generator are constant $\left(n_{D}=\right.$ const);

2. Varying the revolutions of diesel generator $\left(n_{D}=\right.$ var), when the excitation current of traction generator is constant $\left(I_{z}=\right.$ const, $\Phi=$ const $)$.

Let us consider a technique of determining braking characteristics of traction motors by analysing a circuit presented in Fig 10 [7].

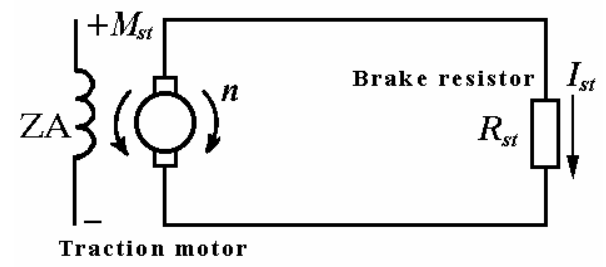

Fig 10. Traction motor operating in rheostatic braking mode

The electromagnetic moment developed on the motor shaft can be expressed by the formula:

$$
M_{s t}=\frac{C_{m}}{\eta_{e m}} I_{s t} \Phi,
$$

where $C_{m}=\frac{p N}{2 \pi a}$ is constant of the motor; $\eta_{e m}$ is coefficient of mechanical and magnetic losses of the motor; $p$ is the number of pole pairs; $N$ is the number of armature winding conductors; $a$ is the number of parallel branches; $I_{s t}$ is motor's armature (braking) current in rheostatic braking, $\mathrm{A} ; \Phi$ is magnetic pole current, $\mathrm{Wb}$.

The electromotive force of traction motor (operating in generator mode) $E=C_{e} \Phi n$ is obtained from the voltage balance equation:

$$
C_{e} \Phi n=I_{s t}\left(R_{s t}+r_{i n k}+r_{p p}\right)=I_{s t} R_{s t}^{\prime},
$$

where $C_{e}=\frac{p N}{60 a}$ is motor constant; $n$ is armature speed, $\mathrm{rpm} ; R_{s t}$ is braking rheostat resistor, $\Omega ; r_{i n}$ is armature winding resistor, $\Omega ; r_{p p}$ is resistor of additional poles, $\Omega ; R_{s t}^{\prime}$ is total impedance of braking rheostat and armature circuit, $\Omega$.

Thus, braking current can be expressed as follows:

$$
\begin{gathered}
I_{s t}=\frac{C_{e} \Phi n}{R_{s t}^{\prime}}, \\
\Phi=\frac{I_{s t} R_{s t}^{\prime}}{C_{e} \eta_{e m}} .
\end{gathered}
$$

Then, the braking moment directed oppositely to the rotation of the motor armature $n$ can be expressed, based on (13), in the following way:

$$
\begin{aligned}
& M_{s t}=\frac{C_{e} C_{m}}{R_{s t}^{\prime} \eta_{e m}} \Phi^{2} n=K n, \text { when } \Phi=\text { const } ; \\
& M_{s t}=\frac{C_{m} R_{s t}^{\prime}}{C_{v}^{e} \eta_{e m}} I_{s t}^{2} \frac{1}{n}=K \frac{1}{n}, \text { when } I_{s t}=\text { const . }
\end{aligned}
$$

As seen from the formulas (17) and (18), the linear braking moment relationship (see a straight line OA in Fig 11) is obtained, when the excitation flux $\Phi=$ const, while the hyperbolic relationship between the braking moment and the armature speed of the motor is established, when $I_{s t}=$ const.

To obtain diesel locomotive's braking characteristic, i.e. the relationship between the braking force on the wheelsets' rolling surface and the locomotive speed $B_{s t}=f(\mathrm{v})$, the following formulas can be used [8]:

$$
B_{s t}=\frac{2 M_{s t}}{D} \frac{\mu m}{\eta_{p}},
$$

where $\mu$ is gear ratio of the gear drive; $D$ is wheelset diameter, $\mathrm{m} ; m$ is the number of traction motors; $\eta_{p}$ is gear drive efficiency.

The locomotive speed, $\mathrm{km} / \mathrm{h}$, is expressed as:

$$
v=0.188 \frac{D n}{\mu} \text {. }
$$

Taking into account formulas (19) and (20), we get:

$$
\begin{aligned}
& B_{s t}=10.6 \mu^{2} \frac{C_{e} C_{m} m}{R_{s t}^{\prime} D^{2} \eta_{e m} \eta_{p}} \Phi^{2} v, \\
& B_{s t}=0.378 \frac{C_{m} R_{s t}^{\prime} m}{C_{e} \eta_{e m} \eta_{p}} \frac{I_{s t}^{2}}{\mathrm{v}} .
\end{aligned}
$$

By using the above formulas, braking characteristics of a diesel locomotive $B_{s t}=f(\mathrm{v})$ can be obtained. When the excitation flux $\Phi=$ const, braking force is proportional to speed and can be depicted as a straight line, beginning at the origin of coordinates. When the 
braking current is constant $-I_{s t}=$ const, $B_{s t}=f(\mathrm{v})$ is inversely proportional to speed, while the hyperbolic function changes (see curve AD in Fig 11).

The value of the strongest traction motor's excitation current defines the boundary region $\mathrm{OA}$ of the braking characteristic $B_{s t}=f(v)$ (see Fig 11).

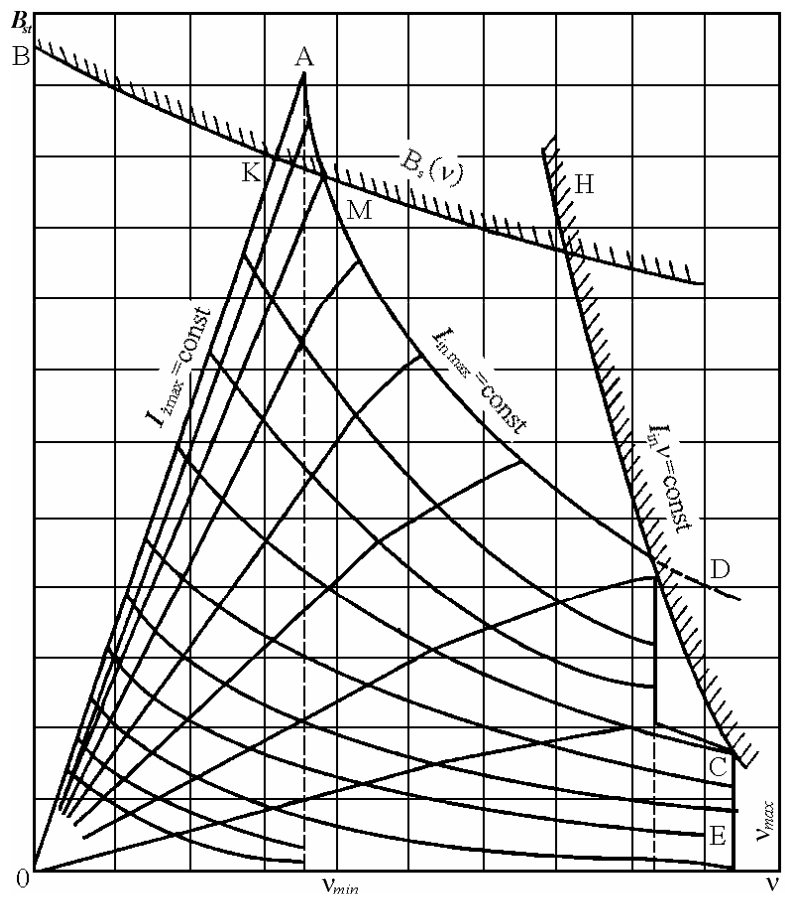

Fig 11. Braking characteristics of traction motor: OA is restriction imposed by the strongest excitation current; $\mathrm{AD}$ is restriction imposed by the strongest armature current; $\mathrm{HC}$ are restrictions imposed by commutation; $B_{s}(v)$ is restriction imposed by adhesion with rail $\mathrm{KM}$

The magnitude of the strongest traction motor's excitation (short-term or long-term) flux defines the boundary region $\mathrm{AD}$ of the braking characteristic $B_{s t}=f(\mathrm{v})$, which is determined by the limiting temperature of the motor's armature windings and braking rheostats.

When the speed is high, braking force is restricted by the conditions of commutation (the curve $\mathrm{HC}$ ) and traction motor's collector (the curve CE).

The restriction of braking force imposed by the conditions of adhesion with rail $B_{s}(v)$ follows the relationship between the adhesion coefficient $\psi_{k}$ and speed (the curve KM).

The analysis of braking characteristics has shown that braking force can be regulated by varying the braking current $\mathrm{I}_{\mathrm{st}}$ or excitation flux $\Phi$. Ideally, braking force can be maintained constant when the speed is varying.

To obtain the required braking characteristics of a locomotive, the automatic systems (ARS) of controlling speed and braking force are used. These systems, maintaining the feedback with the controlled magnitude, i.e. braking force, change the braking current $I_{s t}$ or excitation flux $\Phi$ of the circuit so that the braking force would be controlled:

1. when a locomotive is moving down the slope at constant slowing down speed $v=$ const up to complete stopping;

2. in other cases of braking (e. g. in order to slow down the locomotive speed according to light signals, etc.), depending on the type of characteristics $B_{s t}(v)$.

In the case of emergency braking, braking force is regulated according to the highest values of armature current $I_{i n}$ and excitation current $I_{z}$, i.e. limiting commutation conditions.

\section{Conclusions}

1. Electromagnetic braking of the high-speed rail transport is the main method ensuring the stability of braking process.

2. High accuracy of braking force regulation helps decrease longitudinal dynamic forces developed in stepwise pneumatic braking.

3. Electrodynamic braking control system can be effectively integrated into the global transport control system.

4. When an electrodynamic braking is introduced, the economic indices of the system will be considerably improved. The use of modern microprocessorbased control systems for regeneration braking of high-speed trains under the conditions of heavy railway traffic allows $25-40 \%$ of electric power to be returned to the power system. The power stored in traction is fully utilized in rheostatic braking.

5. The required braking forces can be obtained in a wide range, with regeneration braking used in a high-speed range and rheostatic braking - in a lowspeed range.

6. Mechanical braking, commonly used now, should be kept in reserve as a technique duplicating the main braking method and used to completely stop a locomotive when its speed is $5-2 \mathrm{~km} / \mathrm{h}$.

7. An advanced method of braking force control in rheostatic braking by uniformly changing the main circuit parameter - rheostat resistor value in a noncontact way by means of semiconductor switches is suggested.

8. A scheme of upgrading electric power system aimed at returning the power obtained in regeneration braking to the system is offered.

9. A scheme of braking force stabilization in regeneration braking (when contact system voltage changes) is presented.

10. Electrodynamic braking with the specified acceleration (in this case, the acceleration value is negative) is ensured, helping to avoid the action of a longitudinal dynamic force on rolling stock. In this way, the deterioration of the elements of automatic clutches and chassis is reduced, while travel condi- 
tions for passengers become more comfortable (because jerking is eliminated).

11. The power stored in the locomotive in traction is completely utilized. Thus, the power obtained from burning oil is used in diesel locomotives, while that obtained from the electric power and reaching more than $10 \mathrm{MW}$ is utilized by electric locomotives and electric trains (power consumption of the latter is very high). When ordinary mechanical braking is applied, no useful work is done by the power and it is not used in braking.

\section{References}

1. LINGAITIS, L. P.; LIUDVINAVIČIUS, L. Electric drives of traction rolling stocks with AC motors. Transport, 2006, Vol XXI, No 3, p. 223-229.

2. THEEG, G.; BAUMGARTNER, S.; MASCHEK, U. Comparison of signalling systems for high-speed train movements. Rail International, 2006, No 10, p. 65-73 (in Russian).

3. KAGEYAMA, I. On a control of tyre force coefficient for vehicle handling with neural network system. In Proc. of $13^{\text {th }}$ IAVSD Symposium, China, 1993, p. 31-34.

4. SMILGEVIČIUS, A. Micromachines for automation. Vilnius: Technika, 2005. 343 p. (in Lithuanian).

5. Mitsubishi Electric Transportation Systems. Japan, 2003, p. 2-21.

6. MAZARAS, S. Electric motors. Part 1. Vilnius: Mokslas, 1989. 303 p. (in Lithuanian).

7. VILKIEVIČ, B. I. Automatic control of electric drives and electric circuits of diesel locomotives. Moscow: Mashinostrojenie, 1980. 224 p. (in Russian).

8. STREKOPYTOV, V. V.; GRISHCHENKO, A. B.; KRUCHEK, V. A. Electric drives of the locomotives. Moscow: Marshrut, 2003. 305 p. (in Russian). 